\title{
A Critical Analysis of Selected Policy Making Decisions in the US and the UK with Regard to the Implementation of Information and Communication Technology (ICT) in National State Primary and Secondary School Education Systems
}

\author{
Mark Brooke \\ Department of Linguistics, Hong Kong Institute of Education, Hong Kong \\ Email: mbrooke@ied.edu.hk
}

Received October $6^{\text {th }}$, 2012; revised November $12^{\text {th }}$, 2012; accepted November $20^{\text {th }}, 2012$

\begin{abstract}
Information and Communication Technology has played an important and pervasive role in modern business and everyday living over the last decade and more. The industry accounts for trillions of annual revenue. Yet, it has proved hard for a similar role for Information and Communication Technology (ICT) to emerge in education. In this paper, I will argue that policy regarding ICT use at national state levels in the UK and the US has striven to create, and continues to perpetuate, a system of education with technological divisions of labour, and marginalized innovative and communicative practical uses of technology for enhancing education in schools.
\end{abstract}

Keywords: Information; Communication Technology; Policy Studies; Lifeworld; Virtual Learning Environment; Interactive White Board

\section{Understanding Policy Making}

Ball \& Shilling (1994) argue that nation states and their social systems are determined in terms of their ideological, political and economic structures. Policy making (a visualization of how a society is managed) and in particular for this paper, educational policy making, can also be analyzed at these levels. At the economic level, it is important to analyze to what extent education contributes to productivity and capital gain; at the political level, it is important to examine the governance of education and the interventions made by influential groups in the policy process; at the ideological level, it is important to analyze the discourse in which educational policy making is conceived and debated, and to examine how the dominant culture is transmitted in society. Studying each of these elements in isolation, as well as the nature of the interrelationships between them can lead to an in-depth understanding of educational policy (Ball, 1990: 11). In addition, it is important to uncover any emerging ideologies both, overt and covert, that exist in educational practice which contradict the dominant. These emerging ideologies are represented by minorities in society and they tend to fundamentally oppose the status quo seeking to undermine its authority for the betterment of society. In this way, the complex which makes up the educational scene is more aptly understood.

In Section 2, selected educational policy making regarding technology in education since the new millennium in both the US and the UK will be presented and discussed. This analysis will offer a snapshot of the dominant and emerging ideologies that have existed over the last decade and which continue to be prominent today. It can be seen that although much has been said in this field, little has changed. From the economic perspective, technology in education remains predominantly driven by profiteering campaigns. From the political perspective, these governments continually implement policies to integrate evernewer technologies in state school education. From the ideological perspective, the dominant rhetoric remains that a system is being constructed that will lead at a global level producing citizens for the future. Section 2 then goes on to argue that, alongside this dominant policy complex, exists an emerging ideology seeking to effectively capture the best technology has to offer for learning. This ideology can be seen to be marginalized and this marginalization can be witnessed since the growth of technology use in education.

\section{Empirical Analyses}

\section{Information Computer Technology (ICT) in Education in the US and UK at the Turn of the Millennium}

Over ten years ago, educational computing in the US and the UK was reported to be an imposed and novel "outsider" in the pedagogy of schools. Citing other studies (Elmore \& McLaughlin, 1988; Sarason, 1971; Spencer, 2000; Tyack \& Cuban, 1995; and Zilversmit, 1993), as well as their own, Cuban et al (2001) documented some of the history of classroom reform with regard to technology in the US. The authors conducted qualitative and quantitative research in Silicon Valley, which is still today the home to thousands of computer and Internet companies, in two high schools "Flatland" and "Las Montanas", nestled in two Silicon Valley neighborhoods filled with modest to affluent homes and located eight miles apart, interviewing teachers, students, and administrators, and conducting classroom observations, reviews of school documents, and surveys with both teachers and students. Following this research, they concluded 
that technology was seldom used effectively in class. When it was used, the teachers were not creative but conducted tried and tested methods from their practice.

They reported (2001: 14):

"When we shadowed teachers and students, all but a few of the teachers in both schools used a familiar repertoire of instructional approaches. These included lecturing, conducting a discussion, reviewing homework, working on assignments, and occasionally using overhead projectors and videos."

A qualitative study of a teacher named Piro, who Cuban et al. (2001) labelled as marginalized (and because of this, called her a "greenhorn" or "lone ranger"), revealed how students could optimally use computers. Piro set up frequent computer projects to do research tasks in groups on the web and asked them to present their findings using a programme such as PowerPoint. While her students were working together in groups, Piro acted as the facilitator, moving from group to group to support and challenge as they proceeded (2001: 814). However, this type of usage was reported to be extremely rare. In reality, the occasional serious, well-grounded educational uses of computers had marginal to no impact on established teaching practices. The authors concluded that contrary to establishment claims, (2001: 814): "a classroom revolution has not occurred."

The vast majority of teachers in the two high schools adapted technology to fit the familiar practices of teacher-centered instruction (Ibid: 825). Cuban et al argued that their findings were similar to other reports in the literature (Cohen, 1987, 1988, 1990; Goodlad, 1984; Rosenholtz, 1989; Sarason, 1971, 1993). Those who predicted that new technologies would eventually transform teacher-centered practices into student-centered ones (Cetron \& Gayle, 1996; International Society for Technology in Education, 1999; Papert, 1993; Mehan, 1989; National Educational Assessment Program, 1994, 1996; Schofield, 1995) had been proven wrong.

Cuban et al., among other critics (Anderson \& Ronnkvist, 1998; Becker, Ravitz, \& Wong, 1999a, 1999b; Sandholtz, Ringstaff, \& Dwyer, 1996; Schofield, 1995), argued that there were several serious dilemmas. One such dilemma was that the design of the reform was heavily "top-down". It did not involve teachers in the process of change. Other reasons were, first that teachers did not have the time to find and evaluate software in their already busy schedules; second, computer and software training was seldom offered at convenient times; third, training that was available was often irrelevant to teachers' specific needs; and fourth, it was repeatedly stated from administrators, coordinators, teachers, and students, that constant replacement of obsolete software and machines meant that keeping up with technology was a constant pressure. Contrary to often reported reasons why teachers' use of computers was low, these authors did not find that teachers' age, experience, or gender are factors; nor did they find that there was teacher resistance due to technophobia.

In order to facilitate change, Cuban et al (2001: 830) concluded:

"Fundamental changes would need to be made in how schools are organized, how time is allocated, and how teachers are prepared. Hardware manufacturers, software firms, and telecommunication companies would need to improve product reliability to limit the defects in their wares, expand technical support to teachers, increase speed of Internet connection at little cost to schools, and test software on consumers prior to marketing them to district and state administrators."

Watson's (2001) study revealed the same problems in the UK. Research showed that teachers were not impressed by change that appeared to focus on what the technology could do rather than on the processes of learning. Watson (ibid) argued that this was not surprising with applications that were originnally designed for business. In 1997, Blair (UK Prime Minister, launching the National Grid for Learning, 1997) echoed this notion:

"Technology has revolutionized the way we work and is now set to transform education. Children cannot be effective in tomorrow's world if they are trained in yesterday's skills.”

According to Watson (2001: 253), each new initiative was launched with little evidence of evaluating or analysing the last. Indeed research reported that the impact of IT on schools in the UK remained a resolutely disappointing one (Gardner et al., 1993; Stevenson, 1997; Watson, 1993, 1995, 1998; Williams et al., 2000). Most analyses on the apparent reluctance of teachers to use IT in their classrooms, related this to a deficit model of teachers who were characterized as technophobic, or too traditional in their teaching style, or reluctant to adopt change. However, in agreement with Cuban et al. (2001), Watson (2001) challenged the governing bodies' oversimplistic and rather patronizing attack on teachers as to the cause of the poor state of affairs.

\section{Information Computer Technology (ICT) in Education in the US and UK in the Last Decade}

The US Department of Education's National Center for Education Statistics (US Dept of Education facts and figures, retrieved July, 2012) states that $100 \%$ of US schools are now wired to the Internet. In addition, US national statistics reveal that the ratio of student to computer is around 3 to 1 . This change was brought about by intense promotion by business leaders, policy makers, and parents. Similarly, the Minister of State for Schools and Learners in the UK, Jim Knight, offered a response to the launch of the second phase of the "Harnessing Technology Strategy", stating that "technology is no longer optional” (cited in Becta report, 11/2008). In 2009 a report from "Becta", the British Educational Communications and Technology Agency

(http://foi.becta.org.uk/content_files/corporate/resources/policy _and_strategy/board/0610-oct/tech_learn_landscape.pdf, published 11/08; retrieved April, 2009), the government agency that lead the UK's national drive to ensure the effective and innovative use of technology throughout learning, stated that schools and FE institutions spend around 7\% of their total funding on IT. This represents a national figure of around 984 million pounds, quite a sum for the British Educational Suppliers Association (Besa).

Even with an ever-increasing "e-enabled capability", the report stated that there still appeared to be a sizeable number of practitioners in schools and colleges who did not fully engage with ICT and digital resources (as shown above, the "ambivalent" scores were reported to be higher than the "enthusiastic" 
scores) and the majority of ICT use continued to be for wholeclass teacher displays and presentations. In the same way, the latest edition in 2012 of the ICT for Education in the UK journal (http://www.ictforeducation.co.uk/), recently published an article on ICT investment in schools by Ray Barker, the director of the Besa. It states that despite years of spending on ICT, even to the extent of "saturation” (Barker's term, 2012: 9), 70\% of primary and $55 \%$ of secondary school teachers require training in the use of technology for education. It is written (2012: 9):

"While procurement of these types of technology is encouraging, it is training that stands out as an area in need of investment.”

After more than 20 years, it is still common for training in the use of technology in these schools to be generic and more relevant to administrative tasking rather than pedagogy. Therefore, research on the impact of ICT on teaching and learning has continued to report disappointment.

Two examples of massive investment in technology for education in the UK and the US are first Virtual Learning Environments, also known as Learning Management Systems and second Interactive Whiteboards.

\section{The Virtual Learning Environment (VLEs)}

In 2008, Becta (2008: 3) claimed:

"Improving the quality of discussion between parents and learners about their education makes all the difference to what learners achieve. Technology can help you provide useful information at an appropriate time, to improve this dialogue."

To do this, the use of online virtual learning environments (VLEs) such as Moodle and Blackboard is under development. In the 2009 Ofsted report on "Virtual learning environments: an evaluation of their development in a sample of educational settings", it is stated

"the introduction of VLEs is at an early stage in most contexts."

In fact, these systems are not being utilized, particularly in Primary schools, because teachers are wary about using them. This is understandable given what Ofsted states in the same publication under the heading of "emerging technologies". In this section, there is a report on Cloud Computing. The concept of Cloud Computing at the time of writing this article (July, 2012) was also starting to creep into educational institutions through the usual handful of case studies conducted by "specially futuristic state schools”, like the one by the Lincoln Specialist Schools Group, who reported effective use of a Business Productivity Online Suite from Microsoft ${ }^{\circledR}$ Online Services. This was deemed more effective than VLEs such as Blackboard or Moodle to manage calendars, rosters, grade books, and communication between school and home as none of the schools" IT departments need to set up or maintain the services themselves. In other words, one driving technology in education policy is already being taken over by another. Thus the VLE, which was originally set up for this kind of operation, and whose effectiveness was still in its early days in December, 2011, seems to be already obsolete.

\section{Interactive Whiteboards (IWBs)}

A key finding from the Department for Education with regards to the use of technology in schools (December, 2011) focuses on the classroom Interactive Whiteboard

"Evidence suggests interactive white boards (IWBs) can foster a more interactive style of whole class teaching through features that encourage student participation in this setting, through the use of touch-sensitive screens.”

However, in the Guardian newspaper, only a few months prior to this (08/2010) and just as Becta was being closed down in the UK as part of government spending cuts, an executive of a major computer supplier made a comment about the interactive whiteboards that schools had been acquiring:

"A lot of schools just use them as a projection screenwhich misses a significant part of the boards' potential for creativity."

(http://www.guardian.co.uk/education/2010/aug/17/becta-sch ools-computers-technology-creative-retrieved 18/06/2012)

\section{Discussion}

All of these reports demonstrate one thing that is very much reminiscent of Watson (2001) and Cuban et al's (2001) critiques during the last decade. This is that through political policy, the IT world is always one step ahead of educational institutions with its emerging technologies. It is interesting to note the apparent agencyless "emerging" technologies at this point, which seem to occur as processes over time on their own, seemingly evolving in a parallel world. As stated by Fairclough (2003b: 6-7):

"actors in the material processes are non-human, inanimate ('new technologies', 'new markets') or nominalized ('change'), and the actor in the verbal process is 'this new world'. The global space-time is represented as processes without human agency.”

It is as though we cannot control this tide of technical change. As a result, as Ball \& Shilling (1994: 11-12) note:

"Not surprisingly, many teachers appear weary and wary, stressed and depressed, alienated and bitter. They are faced with threats to their autonomy and status, and livelihood in some cases, but are expected to respond constructively and intelligently to make sense of the uncertainties, incoherence and complexity of change."

With the constant ideological discourse relating to the speed of processing, multimedia, and broadband, ICT is still, and always has been, synonymous in schools with technical matters and with the associated power base for those "in the know" and who "understand these things". This has been both overtly and covertly damaging (Watson, 2001). As a result, many teachers own and use computers for their own administrative work, but never use them in their classrooms. Similarly to Cuban et al. (2001), Watson (2001) argues that curriculum change theories have generally asserted that once a small cohort of innovators emerges, their adoption of the innovation cascades through their peer group of subject teachers. In particular it is these teachers who recognize and enjoy the pedagogic potential of ICT because it relates to their own philosophical underpinnings 
about teaching and the nature of their subject (Watson, 1993). But these "lone rangers" are a very tiny minority in schools. In the ICT for Education in the UK journal (2012: 4)

(http://www.ictforeducation.co.uk/), Jodie Collins writes that her innovative use of ICT meant that she was:

"given the role of being a non class-based ICT specialist teacher. In this role, I was able to teach children across the school using IT. In order to start showcasing work online for everyone to see, I started

www.gettingintoliteracy.com.”

The author does not state how many of her colleagues have used what she now showcases but this author can imagine that the majority of them would like to become more involved but unfortunately they cannot afford the time. Jodie Collins has now been marginalized. If she had remained in her role as a classroom teacher using innovative practices, change may have come from her students reporting to her other colleagues what she did. Now, students do not expect such innovations from their other teachers because Jodie is "special”.

These few Information Technology (IT) experts are essential commodities, often with predominantly non-educationalist backgrounds but always with an extensive bank of IT metalanguage. Sumner (2001) refers to this phenomenon as a "tendency to closure” and it is very much associated with Bourdieu's (1990) notion of "Cultural Capital". "Cultural capital” is embodied in the individual. Over time, through the following of the state's culture and traditions transmitted through socialization, one forms a "habitus", or a way of thinking, inculcated in society and transmitted to an individual as one takes on a role in society. This role, as is the case with the IT expert in an educational setting, offers the individual an accepted institutionalized persona. By this tendency to closure the individual is seen to possess the necessary academic credentials or qualifications, and is given institutional recognition (the institutionalized state of cultural capital) guaranteeing a certain monetary value or economic capital, for a certain institutional level of achievement. This is done by limiting the technological knowledge teachers have, and the time open to them to increase their knowledge in this field. Just as an IT expert is rarely a teacher, a teacher is rarely an IT expert. In reality, what is observed here is a rigorous division of labour.

By keeping teachers out of the "know-how", a structure of resource dependencies is created. By continually referring to "emerging technologies" a real malaise is perpetuated with regard to the quality of the teaching and learning environment. In a brief outline of the effects of policy change on education in the UK, Ball's (Ball \& Shilling, 1994: 11) description of the never-ending reform package that simultaneously involves the restructuring of the national curriculum, the governance and funding of schools, requirements for changes in student testing, school inspection and the implementation of cutting edge technology and partnered pedagogy is just as valid now as it was then.

These changes, of which technology plays a vital part, are all externally imposed and most have legal status. In addition to this storm of change, there are reformulations, unreasonably short time frames for implementation and a lack of teacher consultation. The nature of schooling is always in rapid transformation. In a long queue, sit first-order reforms followed by feedback, quality control and subsequent second order reforms, and the cycle continues. In the midst of all this, teachers are expected to develop their own professionalism as well as important working relationships with the students, parents, and colleagues around them.

Again, reminiscent of Cuban's (2001) words, what is being focused on is "high access" and "low use", in particular, low communicative, interactive use. An emergent and marginal study of these VLEs, developed by the "Greenhorns" or "Lone Rangers" in educational settings, reveals that if used effectively the VLE can offer deep and meaningful learning through collaboration. In fact, they might provide an unprecedented infrastructure for online learning (Schramm, 2007; Steeples et al., 2007; Bangeni \& Nel, 2007). Lewis and Allan (2005: 45) state:

"Virtual learning environments provide all the facilities that are required to enable a virtual learning community to work together in a private meeting space.”

This is because these environments are multimodal in nature. They involve the interaction of multiple semiotic resources such as spoken and written language through video, audio, discussion forums and blogging for both the presentation and the negotiation of information. As Chun \& Plass (2000: 152) note, they also allow for

"learners to engage in productive tasks and activities in both synchronous and asynchronous methods of student collaboration."

In this way, Bates (1993), like Becta (2008), predicted the possibility for “a networked society”, but for Bates (1993: 249), it is one which not only offers access to knowledge and information but also one which facilitates "humanistic applications of technology". For example, in the UK, the University of Hull has run the "Workforce Development Confederation e-learning strategy (see Lewis \& Allen, 2005: 31):

"To share knowledge and understanding of the underpinning pedagogies that support effective collaborative elearning."

In addition, private "Lone Ranger" groups, such as the "Consultants-E” (www.theconsultants-e.com) are providing training for online facilitators. However, this training requires extra, supplementary effort by teachers outside of their normal teaching duties, and so remains marginalized, even unknown. The dominant ideology with regard to technology builds on a oneway transmissive model and teachers in schools do not have the time to fully understand and experiment with the potentiality of information and communication systems because of the constant policy changes that occur. The IT expert is a result of this and this creates a division of labour linked to technology.

It is possible to explain this state of affairs using Habermas' "Theory of Communicative Action" (1984, 1987), and the dominance that the "System" perpetuates over the "Lifeworld". According to Habermas (ibid), the global community seeks to enhance the quality of its members' lives. It struggles to uphold shared communitarian values and humanistic ideals: clean air; fresh water; biodiversity; unadulterated food; health care; education; child/elder care and productive work. These values and ideals are reflected and acted on collaboratively through "communicative action” through interpersonal relations:

"The actors seek to reach an understanding about the situation and their plans of action in order to coordinate their actions by way of agreement.” (Habermas, 1984: 86) 
Habermas argues that the "System" consciously rejects the ideals of the community and is at constant loggerheads with the "Lifeworld". It is

“... the socio-economic system which provides employment and security in exchange for loyalty.” (Mezirow, 1995: 61)

It is led by the institutions of power and wealth that exist in the world: "multinational corporations, the military and the administration" (Sumner, 2000). It is a minority group which must undermine the community to preserve the status quo and its power. The more communication there is, the more "noise" (Nipper, 1989) there is, in the System. This "noise" is the sound of people interacting. Institutions must monitor and control the degree of this "noise". It could be argued that the perpetuated flood of new technologies and the very "static" (King, 2001) use of these technologies is the System's action to promote policy that restricts the Lifeworld's struggle for expression. The result for pedagogy is that technology is barely used to its potential. Instead, technology is fundamentally used as one-way communication, from sender to receiver or uploader to retriever rather like the "Magistral dialogue", Bakhtin (1981) was so critical of. The social interaction is minimal.

The move away from transmissive views of education toward learner-centered constructivist learning processes implies changes: changes in roles and changes in power structures (Keegan, 1990). A process-driven VLE approach might open the door to widespread communicative interaction between learners. This creation of communities, where people meet to work together and to share experiences might be an undesired phenomenon; one that empowers, emancipates, gives voice, commitment and support. As Campion, (drawing on the work of Ivan Illich) suggests, there are "diametrically opposed interests" in learning (in Evans \& Nation, 1992: 10) and it seems that the Lifeworld has been on the losing side since the turn of the new millennium. One way to examine whether these notions are true will be to observe the future directed policy towards the use of technologies in national educational fields in the US and the UK. It is probable that the communicative use of these tools will remain marginal and that their use in education will die out due to another software or hardware package, which will be claimed to be more effective, before teachers have even had a chance to explore these mediums for the purpose of real teaching and learning.

\section{Conclusion}

In his recent speech for his Digital Literacy Campaign (http://www.guardian.co.uk/education/2012/jan/11/digital-litera cy-michael-gove-speech, retrieved July, 2012), Michael Grove, Minister for Education in an all too familiar language states:

“A Victorian schoolteacher could enter a 21st century classroom and feel completely at home. Whiteboards may have eliminated chalk dust, chairs may have migrated from rows to groups, but a teacher still stands in front of the class, talking, testing and questioning. But that model won't be the same in twenty years' time. It may well be extinct in ten."

However, he also adds in a more reassuring way for teachers:

"Rather than rushing pell-mell after any particular tech- nology, filling school cupboards with today's answer to Betamaxes and floppy discs, we need to ask ourselves a fundamental question. What can technology do for learning?”

He goes on to argue that policy makers are now taking a step back from the constant flux of change to offer time for educators to reflect on how technology can be used at the grass roots. He pinpoints teacher action research projects by teachers for teachers, for example, a great deal of teachers are now sharing their best practices online; students are using electronic voting pads to provide teachers with immediate feedback during classes; teachers are trialing gaming software for Maths and English classes; VLEs are being used for online assessments through which an individual student's progress can be carefully monitored. Although these uses demonstrate some new benefits to education, they do not reveal how Grove intends to change "that model" that he refers to above.

It is this author's opinion Grove masterfully assures the two major stakeholders in this issue: big business and teachers. However, what can be observed from this diplomatic discourse is that no matter the modernity of the age, the true nature of education, as with all human growth, is based on human contact, whether face to face or online, whether synchronous or asynchronous. There is little more that can be done today to fundamentally change the different ways that teachers and learners interact. The question is whether the policy-makers wish to promote "noise" in the future or to contain it. It seems that if teachers are now happy using "electronic voting pads" in class rather than simply asking students to raise their hands and speak out about their classroom experiences, they would rather contain it.

\section{REFERENCES}

Anderson, R., \& Ronnkvist, A. (1998). The presence of computers in American schools (Rep. No. 2). Teaching, learning and computing: 1998 national survey. Irvine: Centre for Research on Information Technology and Organizations, University of California.

Bakhtin, M. M. (1981). The dialogical imagination. Austin, TX: University of Texas Press.

Ball, S. (1990). Politics and policy in education. London: Routledge.

Ball, S., \& Shilling, C. (1994). At the crossroads: education policy studies. British Journal of Educational Studies, 42, 1-5. doi:10.1080/00071005.1994.9973979

Bates. T. (1993) Theory and practice in the use of technology in distance education. In D. Keegan (Ed.) Theoretical principles of distance education (pp. 213-233). London: Routledge.

Becker, H., Ravitz, J., \& Wong, Y. (1999a). Teaching, learning and computing; 1998 national survey. Irvine: Centre for Research on Information Technology and Organizations, University of California, University of Minnesota.

Becker, H., \& Wong, Y. (1999b). Teacher and teacher-directed student use of computers and software (Rep. KO. 3). Irvine: Centre for Research on Information Technology and Organizations, University of California, University of Minnesota.

Becta Report (2008). "Harnessing Technology Strategy”, stating that "technology is no longer optional".

http://foi.becta.org.uk/display.cfm?resID=37952

Bourdieu, P., \& Passeron, J. C. (1990). Reproduction in education, society and culture. London and Beverly Hills: Sage Publications.

Bowe, R., Ball, S. J., \& Gold, A. (1992). Reforming education and changing schools: Case studies in policy sociology. London: Routledge.

Cetron, M., \& Gayle, M. (1996). Educational renaissance: Our schools at the turn of the twenty-first century. New York: St. Martin's Press. 
Chun, D. C., \& Plass, J. L. (2000). Networked multimedia environments for second language acquisition. In M. Warschauer, \& R. Kern (Eds.), Cambridge applied linguistics series (pp. 151-170). Cambridge: Cambridge University Press.

Clegg, S. R. (1989). Frameworks of power. London: Sage.

Clegg, S. R. (1989). Organization theory and class analysis: New approaches and new issues. Berlin: De Gruyter.

Cohen, D. (1987). Educational technology, policy, and practice. Educational Evaluation and Policy Analysis, 9, 153-170.

Cohen, D. (1988). Teaching practice: Plus que ca change. In P. Jackson (Ed.), Contributions to educational change (pp. 27-34). Berkeley, CA: McCutchan.

Cohen, D. (1990). Educational technology and school organization. In R. Nickerson, \& P. Zodhiates (Eds.), Technology in education: Looking toward 2020 (pp. 231-264). Hillsdale, NJ: Erlbaum.

Consultants-E (2009). www.theconsultants-e.com

Cuban, L., Kirkpatrick, H., \& Peck, C. (2001). High access and low use of technologies in high school classrooms: Explaining an apparent paradox. American Educational Research Journal, 38, 813-834. doi:10.3102/00028312038004813

Dale, R., \& Ozga, J. (1991). Understanding education policy: Principles and perspectives (Course E333 Module 1). Milton Keynes: Open University Press.

Evans, T., \& Nation, D. (1992). Theorising open and distance education, Open Learning, 7, 3-13. doi:10.1080/0268051920070202

Goodlad, J. (1984). A place called school. New York: McGraw-Hill.

Habermas, J. (1984). The theory of communicative action. Boston, MA: Beacon Press.

Denzin, N. K., \& Lincoln, Y. S. (2003). The landscape of qualitative research theories and issues. Thousand Oaks, CA: Sage.

Habermas, J. (1987). The theory of communicative action, Boston, MA: Beacon Press.

Keegan, D. (1990) Foundations of distance education (2nd ed.). New York: Routledge.

Lewis, D., \& Allan, B. (2005). Virtual learning communities: A guide for practitioners. Oxford: Open University Press.

Mehan, H. (1989). Microcomputers in classrooms: Educational technology or social practice? Anthropology and Education Quarterly, 20, 4-22. doi:10.1525/aeq.1989.20.1.05x12081

National Educational Assessment Program (1994). Reading assessment. Princeton, NJ: Educational Testing Service.

National Educational Assessment Program (1996). Math assessment. Princeton, NJ: Educational Testing Service.
Papert, S. (1993). The children s machine: Rethinking school in the age of the computer. New York: Basic Books.

Quinn, M. (1999). Green with envy. San Jose Mercury News, 1, 8-10A.

Quinn, M., \& Lafleur, J. (1999). Money, money, everywhere so why don't you feel rich? San Jose Mercury News, 17-18.

Rosenholtz, S. (1989). Teachers' workplace: The social organization of schools. New York: Longman.

Sarason, S. (1971). 7be culture of the school and the problem of change. Boston, MA: Allan and Bacon.

Schofield, J. (1995). Computers and classroom culture. London: Cambridge University Press. doi:10.1017/CBO9780511571268

Stevenson, D. (1997) Information and communications technology in UK schools: An independent inquiry. London: Independent ICT in Schools Commission.

Sumner, J. (2000). Serving the system: A critical history of distance education. Open Learning, 15, 267-285. doi:10.1023/A:1009636417727

National Center for Education Statistics, Institute of Education Sciences (2006). Internet access in US public schools and classrooms: 19942005 (NCES 2007-020). Washington, DC: National Center for Education Statistics, Institute of Education Sciences.

US Department of Education's Institute of Education Sciences (2005). Computer technology in the public school classroom: Teacher perspectives. http://www.ed.gov/about/offices/list/opepd/ppss/reports.html

Watson, D. M. (1993). The impact report: An evaluation of the impact of information technology on children's achievements in primary and secondary schools. London: Department for Education and King's College Centre for Educational Studies.

Watson, D. M. (1993). Do enthusiastic users inhibit change? In D. C. Johnson, \& B. Samways (Eds.), Informatics and changes in learning (pp. 269-276). Amsterdam: Holland.

Watson, D., \& Tinsley, D. (1995). Integrating information technology into education. London: Chapman and Hall.

Watson, D. M. (1998). Blame the technocentric artefact! What research tells us about problems inhibiting teacher use of IT. In G. Marshall, \& M. Ruohonen (Eds.), Capacity building for it in education in developing countries (pp. 185-192). London: Chapman and Hall.

Watson, D. M. (2001). Pedagogy before technology: Re-thinking the relationship between ICT and Teaching. Education and Information Technologies, 6, 251-266. 